\title{
The sports drink as a functional food: formulations for successful performance
}

\author{
R. J. Maughan* \\ University Medical School, Fosterhill, Aberdeen AB25 2ZD, UK
}

Functional foods are foods, or parts of foods, consumed as part of the daily diet that are designed and processed to provide health benefits for the consumer. There is a growing interest in functional foods for athletes, where the aim is not to improve health, but to improve performance in sport. An enormous number of different products are on offer, but in most cases the advertised benefits are not substantiated by a body of scientific evidence. The support for many products is based on circumstantial evidence or on reports of the effects of an active component, which is usually present in amounts far below those that have been shown to be effective in improving performance.

Many food items consumed by athletes become popular because of supposed benefits, and aggressive marketing techniques can be extremely successful in boosting sales. Bananas have achieved cult status among tennis players and cyclists; they are seen as good sources of carbohydrate (which is true, provided they are well ripened) and $K$ (which is not true; they do contain $K$, but not in greater amounts than many other fruits and, in any case, there is no obvious benefit to be obtained from increasing the dietary $\mathrm{K}$ intake).

One of the few nutritional products aimed at athletes that has been subjected to thorough scientific evaluation and has been shown to be effective is the sports drink. The success of these products is readily apparent from the sales pattern, which shows a rapid and continuing growth in the UK and worldwide. Although the formulation of most of the major commercial products is generally rather similar, there are many variants with different compositions and, therefore, with different functional characteristics. Manipulation of the formulation by changing the nature and concentration of the components can allow these drinks to be tailored to suit individual circumstances, and it is this infinitelyvariable combination that will determine the efficacy of the endproduct.

\section{Purpose of sports drinks}

The aim of the athlete who ingests drinks before, during or after training or competition is to improve performance, and this can be achieved by minimizing the impact of the factors that cause fatigue and impair the performance of skilled tasks. The two factors that have been considered to contribute most to the onset of fatigue in exercise are the depletion of the body's carbohydrate reserves and the onset of dehydration resulting from the loss of water and electrolytes in sweat (Maughan, 1994). In addition, it is becoming increasingly recognized that there may be a central component to fatigue, in which the fatigue signals arising from metabolic events in the periphery are modulated by events occurring within the central nervous system (Davis, 1996). No single factor is likely to be identified as the only cause of fatigue in most situations, and all the factors previously mentioned are likely to be involved when prolonged exercise is carried out.

Despite the definitive statement by the American College of Sports Medicine (1984) in Position stand on the prevention of thermal injuries in distance running, that cool water is the optimum fluid for ingestion during endurance exercise, there is a substantial body of evidence to support the suggestion that there are good reasons for taking drinks containing added sugars and electrolytes. Commonly-formulated sports drinks are intended to serve a variety of purposes. These include:

supply of substrate, prevention of dehydration, electrolyte replacement, pre-exercise hydration, post-exercise rehydration.

In each of these different situations, the requirements of the ingested beverage are likely to differ in some respects; in addition, because of the biological variability between individuals, no single formulation will meet the needs of all athletes in all situations. Issues of taste preference further complicate the formulation of the ideal product. Although manipulation of the composition to suit the individual circumstances is not possible for the commercial manufacturers, an understanding of the issues involved will allow the consumer to make the best choice from the options available.

\section{Formulation of sports drinks}

The major components of the sports drink that can be manipulated to alter its functional properties are shown in

\footnotetext{
Abbreviations: BCAA, branched-chain amino acids.

*Corresponding author: Professor R. J. Maughan, fax +44 (0)1224 662990, email oem023@ABDN.AC.UK
} 
Table 1. Variables that can be manipulated to alter the functional characteristics of a sports drink
Carbohydrate content: concentration and type
Osmolality
Electrolyte composition and concentration
Flavouring components
Other active ingredients

Table 1. To some extent these factors can be manipulated independently, although addition of increasing amounts of carbohydrate or electrolyte will generally be accompanied by an increase in osmolality, and alterations in the solute content will have an impact on taste characteristics, mouth feel and palatability.

\section{Carbohydrate content: concentration and type}

Carbohydrate ingested during exercise will enter the blood glucose pool, if it is absorbed from the gastrointestinal tract; if performance is limited by the size of the body's limited endogenous liver or muscle glycogen stores, then exercise capacity should be improved when carbohydrate is consumed. Several studies have shown that the ingestion of glucose during prolonged intense exercise will prevent the development of hypoglycaemia by maintaining or raising the circulating glucose concentration (Costill et al. 1973; Pirnay et al. 1977, 1982; Erickson et al. 1987). In prolonged exercise, performance, which was measured in most of the early studies as the time for which a fixed power output can be sustained, is improved by the addition of an energy source in the form of carbohydrate; more recent studies have used a variety of different experimental models and have confirmed that this improvement in performance seems to apply also to other exercise models. Beneficial effects of carbohydrate ingestion are seen during cycling (Coggan \& Coyle, 1991) as well as during running (Tsintzsas et al. 1993). This ergogenic effect may be related to a sparing of the body's limited muscle glycogen stores by the oxidation of the ingested carbohydrate (Hargreaves et al. 1984; Erickson et al. 1987), but other studies have failed to show a glycogen-sparing effect of carbohydrate ingested during prolonged exercise, and the consensus view is probably that there is little or no sparing of muscle glycogen utilization, although liver glucose release is slowed (Bosch et al. 1994; McConnell et al. 1994). The primary benefit of ingested carbohydrate is probably its role in supplementing the endogenous stores in the later stages of exercise (Coyle, 1997). It is clear from tracer studies that a substantial part of the carbohydrate ingested during exercise is available for oxidation, but there appears to be an upper limit of about $1 \mathrm{~g} / \mathrm{min}$ to the rate at which ingested carbohydrate can be oxidized, even when much larger amounts are ingested (Wagenmakers et al. 1993).

As well as providing an energy substrate for the working muscles, the addition of carbohydrate to ingested drinks will promote water absorption in the small intestine, provided the concentration is not too high. Because of the role of sugars and $\mathrm{Na}$ in promoting water uptake in the small intestine, it is sometimes difficult to separate the effects of water replacement from those of substrate and electrolyte replacement when carbohydrate-electrolyte solutions are ingested. Below et al. (1995) have shown that ingestion of carbohydrate and water had separate and additive effects on performance capacity (Fig. 1), and concluded that ingestion of dilute carbohydrate solutions would optimize performance. Most reviews of the available literature have come to the same conclusion (Lamb \& Brodowicz, 1986; Murray, 1987; Coyle \& Hamilton, 1990; Maughan, 1994).

In most of the early studies, the ingested carbohydrate was in the form of glucose, but the type of carbohydrate does not appear to be critical, and glucose, sucrose and oligosaccharides have all been shown to be effective in maintaining the blood glucose concentration when ingested during prolonged exercise, and in improving endurance capacity (Maughan, 1994). There are theoretical advantages in the use of sugars other than glucose. Substitution of glucose polymers for glucose will allow an increased carbohydrate content without an increased osmolality, and may also have taste advantages, but the available evidence suggests that the use of glucose polymers rather than free glucose does not alter the blood glucose response or the effect on exercise performance (Ivy et al. 1979; Coyle et al. 1983, 1986; Maughan et al. 1987; Coggan \& Coyle, 1988; Hargreaves \& Briggs, 1988), and similar effects are seen with the feeding of sucrose (Sasaki et al. 1987) or mixtures of sugars (Murray et al. 1987; Mitchell et al. 1988; Carter \& Gisolfi, 1989).

Some studies have suggested that solutions of long-chain glucose polymers are more readily used by the muscles during exercise than are glucose or fructose solutions (Noakes, 1990), but others have found no difference in the oxidation rates of ingested glucose or glucose polymer (Massicote et al. 1989; Rehrer, 1990). Massicote et al.

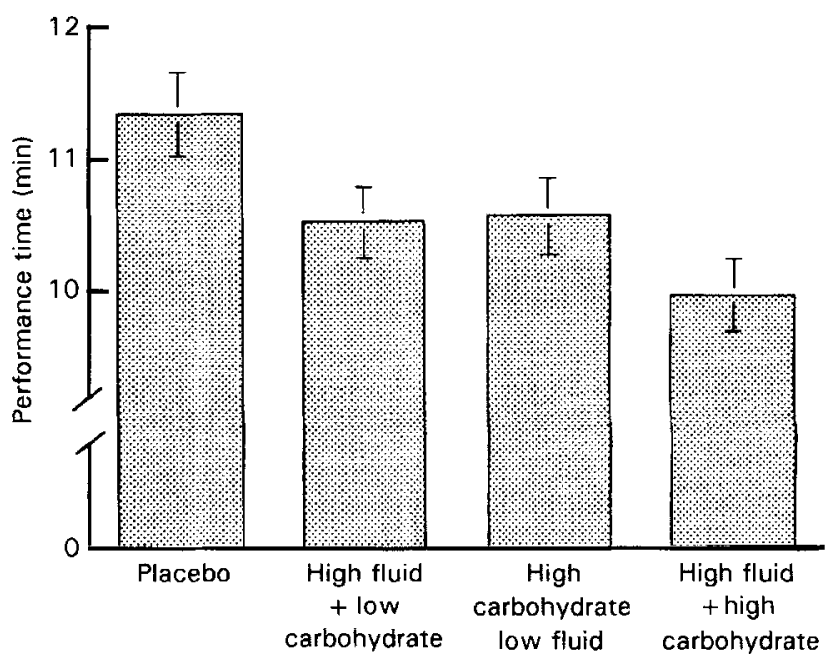

Fig. 1. Effects of ingestion of placebo, low-carbohydrate supplement with a high fluid volume, high carbohydrate in a low fluid volume, or high carbohydrate in a high fluid volume on mean performance in a cycling time trial test. A faster time to complete a fixed amount of work indicated better performance. It is clear that provision of fluid and carbohydrate independently improved exercise performance and that the effects were additive. Values are means and standard deviations are represented by vertical bars. (Data of Below et al. 1995.) 
(1989) also found that ingested fructose was less-readily oxidized than glucose or glucose polymers. Mixtures of glucose and fructose in equal amounts seem to have some advantages; when ingested in combination there is an increased total exogenous carbohydrate oxidation (Adopo et al. 1994). Fructose in high concentrations is generally best avoided on account of the risk of gastrointestinal upset. The argument advanced in favour of the ingestion of fructose during exercise, namely that it provides a readilyavailable energy source but does not stimulate insulin release and consequent inhibition of fatty acid mobilization, is in any case not well founded; insulin secretion is suppressed during exercise. These studies have been reviewed by Maughan (1994). There may be benefits in the use of a number of different carbohydrates, including free glucose, sucrose and maltodextrin; this has taste implications, which may influence the amount consumed, and, by limiting the osmolality and providing a number of transportable solutes, may maximize the rate of sugar and water absorption in the small intestine (Shi et al. 1995).

The optimum concentration of sugar to be added to drinks will depend on individual circumstances. High carbohydrate concentrations will delay gastric emptying, thus reducing the amount of fluid that is available for absorption, but will increase the rate of carbohydrate delivery. If the concentration is high enough to result in a markedly hypertonic solution, net secretion of water into the intestine will result, and this will actually increase the danger of dehydration. High sugar concentrations $(>100 \mathrm{~g} / \mathrm{l})$ may also result in gastrointestinal disturbances (Davis et al. 1988). Where the primary need is to supply an energy source during exercise, increasing the sugar content of drinks will increase the delivery of carbohydrate to the site of absorption in the small intestine. Beyond a certain limit, however, simply increasing carbohydrate intake will not continue to increase the rate of oxidation of exogenous carbohydrate (Wagenmakers et al. 1993). Dilute glucoseelectrolyte solutions may also be as effective, or even more effective, in improving performance as more concentrated solutions (Davis et al. 1988), and adding as little as $90 \mathrm{mmol}$ glucose $/ 1$ may improve endurance performance (Maughan et al. 1996).

\section{Osmolality}

It has become common to refer to carbohydrate-electrolyte sports drinks as isotonic drinks, as though the tonicity was their most important characteristic. The osmolality of ingested fluids is important as this can influence the rates of both gastric emptying and intestinal water flux; both these processes together will determine the effectiveness of rehydration fluids at delivering water for rehydration. An increasing osmolality of the gastric contents will tend to delay emptying, and increasing the carbohydrate or electrolyte content of sports drinks will generally result in an increased osmolality. The composition of the drinks, and the nature of the solutes is, however, of greater importance than the osmolality itself (Maughan, 1994).

Although osmolality is identified as an important factor influencing the rate of gastric emptying of liquid meals, there seems to be rather little effect of variations in the concentration of $\mathrm{Na}$ or $\mathrm{K}$ on the emptying rate, even when this substantially changes the test-meal osmolality (Rehrer, 1990). The effect of increasing osmolality is most consistently observed when nutrient-containing solutions are examined, and the most significant factor influencing the rate of gastric emptying is the energy density (Brener $e t$ al. 1983; Vist \& Maughan, 1994). There is some evidence that substitution of glucose polymers for free glucose, which will result in a decreased osmolality for the same carbohydrate content, may be effective in increasing the volume of fluid and the amount of substrate delivered to the intestine. This has led to the inclusion of glucose polymers of varying chain length in the formulation of sports drinks. Vist \& Maughan (1995) have shown that there is an acceleration of emptying when glucose polymer solutions are substituted for free glucose solutions with the same energy density; at low (about $40 \mathrm{~g} /$ ) concentrations, this effect is small, but it becomes appreciable at higher ( 180 $\mathrm{g} / \mathrm{l}$ ) concentrations; where the osmolality is the same (as in the $40 \mathrm{~g}$ glucose/l solution and $180 \mathrm{~g}$ polymer/l solution), the energy density is shown to be of far greater significance in determining the rate of gastric emptying. This effect may be important, therefore, when large amounts of energy must be replaced after exercise, but is unlikely to be a major factor during exercise where more dilute drinks are taken.

Water absorption occurs largely in the proximal segment of the small intestine, and, although water movement is itself a passive process driven by local osmotic gradients, is closely linked to the active transport of solute. Osmolality plays a key role in the flux of water across the upper part of the small intestine. Net flux is determined largely by the osmotic gradient between the lumen contents and intracellular fluid of the cells lining the intestine. Absorption of glucose is an active, energy-consuming process linked to the transport of $\mathrm{Na}$. The rate of glucose uptake is dependent on the lumen concentrations of glucose and $\mathrm{Na}$, and dilute glucose-electrolyte solutions with an osmolality which is slightly hypotonic with respect to plasma will maximize the rate of water uptake (Wapnir \& Lifshitz, 1985). Solutions with a very high glucose concentration will not necessarily promote an increased glucose uptake relative to more dilute solutions, but, because of their high osmolality, will cause a net movement of fluid into the intestinal lumen (Gisolfi et al. 1990). This results in an effective loss of body water and will exacerbate any pre-existing dehydration. Other sugars, such as sucrose (Spiller et al. 1982) or glucose polymers (Jones et al. 1983, 1987) can be substituted for glucose without impairing glucose or water uptake, and may help by increasing the total transportable substrate without increasing osmolality. In contrast, isoenergetic solutions of fructose and glucose are isosmotic, and the absorption of fructose is not an active process in man; it is absorbed less rapidly than glucose and promotes less water uptake (Fordtran, 1975). The use of different sugars which are absorbed by different mechanisms, and which might thus promote increased water uptake, is supported by recent evidence from an intestinal perfusion study (Shi et al. 1995).

Although most of the popular sports drinks are formulated to have an osmolality close to that of body fluids (Maughan, 1994), and are promoted as isotonic 
drinks, there is good evidence that hypotonic solutions are more effective when rapid rehydration is desired (Wapnir \& Lifshitz, 1985). Although it is argued that a higher osmolality is inevitable when adequate amounts of carbohydrate are to be included in sports drinks, the optimum amount of carbohydrate necessary to improve exercise performance has not been clearly established.

\section{Electrolyte composition and concentration}

The available evidence indicates that the only electrolyte that should be added to drinks consumed during exercise is $\mathrm{Na}$, which is usually added in the form of $\mathrm{NaCl}$ (Maughan, 1994). Na will stimulate sugar and water uptake in the small intestine and will help to maintain extracellular fluid volume. Most soft drinks of the cola or lemonade variety contain virtually no $\mathrm{Na}(1-2 \mathrm{mmol} / \mathrm{l})$; sports drinks commonly contain $10-25 \mathrm{mmol} / 1$; oral rehydration solutions intended for use in the treatment of diarrhoea-induced dehydration, which may be fatal, have higher $\mathrm{Na}$ concentrations, in the range $30-90 \mathrm{mmol} / \mathrm{l}$. A high $\mathrm{Na}$ content, although it may stimulate jejunal absorption of glucose and water, tends to make drinks unpalatable, and it is important that drinks intended for ingestion during or after exercise should have a pleasant taste in order to stimulate consumption. Specialist sports drinks are generally formulated to strike a balance between the twin aims of efficacy and palatability, although it must be admitted that not all achieve either of these aims.

When the exercise duration is likely to exceed $3-4 \mathrm{~h}$, there may be advantages in adding $\mathrm{Na}$ to drinks to avoid the danger of hyponatraemia, which has been reported to occur when excessively large volumes of low-Na drinks are taken. Physicians dealing with individuals in distress at the end of long-distance races have become accustomed to dealing with hyperthermia and hypernatraemia associated with dehydration, but it has become clear that a small number of individuals at the end of very prolonged events may be suffering from hyponatraemia in conjunction with either hyperhydration (Noakes et al. 1985, 1990) or dehydration (Hiller, 1989). All reported cases have been associated with ultramarathon or prolonged triathlon events; most of the cases have occurred in events lasting in excess of $8 \mathrm{~h}$, and there are few reports of cases where the exercise duration is less than $4 \mathrm{~h}$. Noakes et al. (1985) reported four cases of exercise-induced hyponatraemia; race times were between 7 and $10 \mathrm{~h}$, and post-race serum $\mathrm{Na}$ concentrations were between 115 and $125 \mathrm{mmol} / \mathrm{l}$. Estimated fluid intakes were between 6 and 12 litres, and consisted of water or drinks containing low levels of electrolytes; estimated total $\mathrm{NaCl}$ intake during the race was 20-40 mmol. Frizell et al. (1986) reported even more astonishing fluid intakes of 20-24 litres (an intake of almost 2.5 litres/h sustained for a period of many hours, which is in excess of the maximum gastric emptying rate that has been reported) with a mean Na content of only 5-10 $\mathrm{mmol} / \mathrm{l}$ in two runners who collapsed after an ultramarathon run and who were found to be hyponatraemic (serum Na concentration $118-123 \mathrm{mmol} / \mathrm{l}$ ). These reports indicate that some supplementation with $\mathrm{Na}$ salts may be required in extremely-prolonged events where large sweat losses can be expected and where it is possible to consume large volumes of fluid. Most carbohydrate-electrolyte sports drinks intended for consumption during prolonged exercise contain $\mathrm{Na}$ at a concentration of about $10-30 \mathrm{mmol} / \mathrm{l}$, which is rather lower than the normal sweat $\mathrm{Na}$ concentration (Table 2). While the formulation of these drinks might represent a reasonable strategy for providing substrates and water (although it can be argued that a higher $\mathrm{Na}$ concentration would enhance water uptake and that a higher carbohydrate content would increase substrate provision), these recommendations may not be appropriate in all circumstances.

Restoration of fluid and electrolyte balance after exercise is an important part of the recovery process, especially when a second exercise session must be performed after a short time interval. Several studies have investigated the effects of ingestion of water or of commercially-available drinks on restoration of fluid balance after exercise-induced dehydration. Costill \& Sparks (1973) showed that ingestion of a glucose-electrolyte solution after dehydration resulted in a greater restoration of plasma volume than did plain water; a higher urine output was observed on the water trial. Gonzalez-Alonso et al. (1992) have recently confirmed that a dilute carbohydrate-electrolyte solution (per litre; $60 \mathrm{~g}$ carbohydrate, $20 \mathrm{mmol} \mathrm{Na}{ }^{+}, 3 \mathrm{mmol} \mathrm{K}{ }^{+}$) is more effective in promoting post-exercise rehydration than either plain water or a low-electrolyte diet cola; the difference between the drinks was primarily a result of differences in the volume of urine produced. Similar results were obtained by Nielsen et al. (1986). In none of these studies could the mechanism of this action be identified, but they did establish that, because of the high urine flow that ensued, even drinking large volumes of electrolyte-free drinks did not allow subjects to remain in positive fluid balance for more than a very short time.

Nose et al. $(1988 a, b)$ showed that the ingestion of large volumes of plain water after exercise-induced dehydration results in a rapid fall in plasma osmolality and in the plasma $\mathrm{Na}$ concentration, and both these effects will stimulate urine output. A second consequence of ingestion of plain water is to remove the drive to drink by causing plasma osmolality and $\mathrm{Na}$ concentration to fall. This will tend to prevent complete rehydration when fluid intake is on a volitional basis.

The importance of the addition of $\mathrm{Na}$ to rehydration fluids was systematically evaluated by Maughan \& Leiper (1995) who dehydrated subjects by the equivalent of 20

Table 2. Concentration ( $\mathrm{mmol} / \mathrm{l})$ of the major electrolytes present in sweat, plasma and in intracellular (muscle) water in human subjects*

\begin{tabular}{lccc}
\hline & Plasma & Sweat & Intracellular \\
\hline $\mathrm{Na}$ & $137-144$ & $40-80$ & 10 \\
$\mathrm{~K}$ & $3 \cdot 5-4 \cdot 9$ & $4-8$ & 148 \\
$\mathrm{Ca}$ & $4 \cdot 4-5 \cdot 2$ & $3-4$ & $0-2$ \\
$\mathrm{Mg}$ & $1.5-2 \cdot 1$ & $1-4$ & $30-40$ \\
$\mathrm{Cl}^{-}$ & $100-108$ & $30-70$ & 2 \\
\hline
\end{tabular}

- The values are collated from a variety of sources; for further details see Maughan (1994). 
$\mathrm{g} / \mathrm{kg}$ body mass by intermittent exercise in the heat; subjects then ingested a volume equal to $150 \%$ of the mass loss of one of the test drinks over a $60 \mathrm{~min}$ period and were followed for a further $6 \mathrm{~h}$. The test drinks contained 0,25 , 50 , or $100 \mathrm{mmol} \mathrm{Na} / \mathrm{l}$. Urine output over the subsequent few hours was inversely proportional to the $\mathrm{Na}$ content of the ingested fluid; only when the $\mathrm{Na}$ content exceeded $50 \mathrm{mmol} / \mathrm{l}$ were the subjects in positive $\mathrm{Na}$ balance, and only then did they remain in positive fluid balance throughout the recovery period (Fig. 2).

These observations were confirmed in a further study that systematically varied the volume of fluid ingested as well as the Na content of rehydration drinks administered after induced hypohydration (Shirreffs et al. 1996). Even drinking large volumes (twice the sweat loss) did not allow subjects to remain in positive fluid balance for more than $2 \mathrm{~h}$ when the $\mathrm{Na}$ content of the drinks was low $(20 \mathrm{mmol} / \mathrm{l})$; increasing the $\mathrm{Na}$ content to $60 \mathrm{mmol} / 1$, however, allowed subjects to remain well hydrated when volumes equal to 1.5 times or twice the sweat loss were ingested.

It is clear from the results of these studies that rehydration after exercise can only be achieved if the $\mathrm{Na}$ lost in sweat is replaced as well as the water, and it might be suggested that rehydration drinks should have a $\mathrm{Na}$ concentration similar to that of sweat. However, the $\mathrm{Na}$ content of sweat varies widely (Table 2), and no single formulation will meet this requirement for all individuals in all situations. The upper end of the normal range for $\mathrm{Na}$ concentration $(80 \mathrm{mmol} / \mathrm{l})$, however, is similar to the $\mathrm{Na}$ concentration of many commercially-produced oral rehydration solutions intended for use in the treatment of diarrhoea-induced dehydration, and some of these are not unpalatable. The oral rehydration solution recommended by the World Health Organization for rehydration in cases of severe diarrhoea has a $\mathrm{Na}$ content of $90 \mathrm{mmol} / \mathrm{l}$, reflecting the high $\mathrm{Na}$ losses which may occur in this condition (Farthing, 1994). By contrast, the Na content of most sports

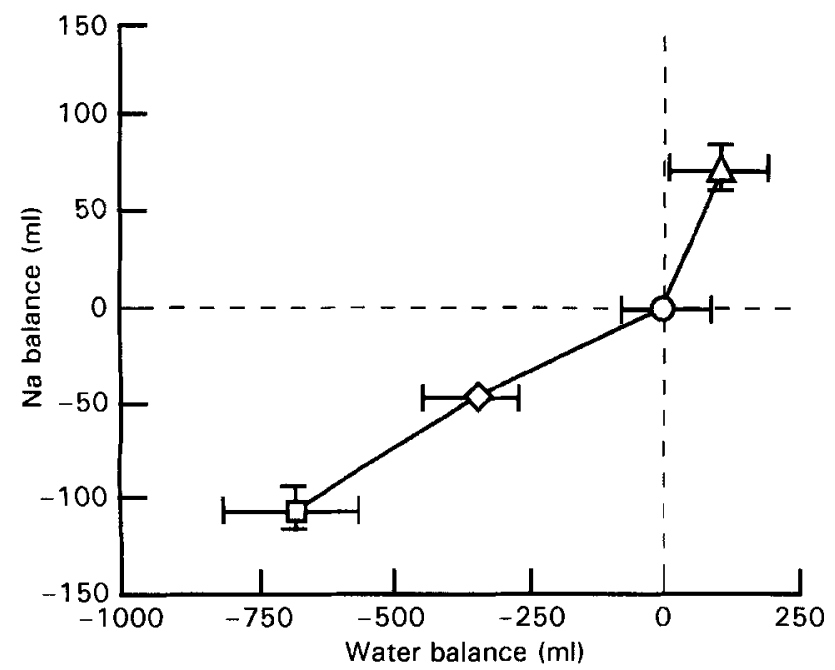

Fig. 2. The relationship between sodium and water balance in subjects who rehydrated with fluids containing varying amounts of sodium $(0(\square), 25(\diamond), 50(O)$ and $100(\triangle) \mathrm{mmol} / \mathrm{l})$ after exercise in the heat. Values are means and standard deviations are represented by vertical bars. (Redrawn from Maughan \& Leiper, 1995.) drinks is in the range of $10-30 \mathrm{mmol} / \mathrm{l}$ and is even lower in some cases; most commonly consumed soft drinks contain virtually no $\mathrm{Na}$ and these drinks are, therefore, unsuitable when the need for rehydration is crucial. The problem with high $\mathrm{Na}$ concentration is that this may exert a negative effect on taste, resulting in a reduced consumption.

It has previously been speculated that inclusion of $\mathrm{K}$, the major cation in the intracellular space, would enhance the replacement of intracellular water after exercise and, thus, promote rehydration (Nadel et al. 1990). Experimental investigation of this possibility suggested that inclusion of $\mathrm{K}$ is as effective as $\mathrm{Na}$ in retaining water ingested after exercise-induced dehydration (Maughan et al. 1994). Addition of either ion will significantly increase the proportion of the ingested fluid which is retained; but, when the volume of fluid ingested is equal to that lost during the exercise period, there is no additive effect of including both ions as would be expected if they acted independently on different body fluid compartments.

$\mathrm{K}$ is normally present in commercial sports drinks in concentrations similar to those in plasma and in sweat (Table 2), but there is little evidence to support its inclusion. Although there is some loss of $\mathrm{K}$ in sweat (about 3-7 mmol/1; Shirreffs \& Maughan, 1997), an increase in the circulating $\mathrm{K}$ concentration is the normal response to exercise; increasing this further by ingestion of $\mathrm{K}$ does not seem useful. The concentration of $\mathrm{K}$ in sports drinks (about 3-6 mmol/1, or about $0.12-0.24 \mathrm{~g} / \mathrm{l}$; Table 2) is close to that present in sweat, but the amounts are small compared with the total daily intake of $K$ for normal sedentary adults in the UK (about $3.2 \mathrm{~g}$; Gregory et al. 1990). Replacement of losses after exercise will normally be achieved from the $\mathrm{K}$ present in foods. A similar situation applies with $\mathrm{Mg}$ replacement, and despite the commonlyheld belief that exercise-induced cramp is associated with a falling plasma $\mathrm{Mg}$ concentration, there is little or no experimental evidence to substantiate this belief (Maughan, 1986). Although a slight decrease in the plasma $\mathrm{Mg}$ concentration is generally observed during exercise, this seems to be the result of a redistribution of the body $\mathrm{Mg}$ stores. There seems to be no good reason for its addition to drinks consumed during exercise (for review, see Maughan, 1994).

Commercially-available sports drinks intended for use by athletes in training and competition are generally rather similar in their electrolyte content, suggesting a consensus, at least among the manufacturers, as to the requirements for electrolyte replacement. There is some debate as to the need to add $\mathrm{Mg}$; this is added in some countries (e.g. Germany) to products that are sold elsewhere without added Mg.

\section{Flavouring components}

Taste is an important factor influencing the consumption of fluids. The thirst mechanism is rather insensitive and will not stimulate drinking behaviour until some degree of dehydration has been incurred (Hubbard et al. 1990). This absence of a drive to drink is reflected in the rather small volumes of fluid that are typically consumed during 
exercise; in endurance running events, voluntary intake seldom exceeds about 0.5 litres/h (Noakes, 1993). Sweat losses normally exceed this, even in cool conditions, and therefore, a fluid deficit is almost inevitable. Several factors will influence palatability, and the addition of a variety of flavours has been shown to increase fluid intake relative to that ingested when only plain water is available. Hubbard $e t$ al. (1984) and Szlyk et al. (1989) found that the addition of flavourings resulted in an increased consumption (by about $50 \%$ ) of fluid during prolonged exercise. More recently, Bar-Or \& Wilk (1996) have shown that during exercise the fluid intake of children presented with a variety of flavoured drinks is very much influenced by taste preference; under the conditions of this study, sufficient fluid to offset sweat losses was ingested only when a grapeflavoured beverage was available. In many of these studies, the addition of carbohydrates and/or electrolytes accompanied the flavouring agent, and the results must be interpreted with some degree of caution.

Given the need to add electrolytes to fluids intended to maximize the effectiveness of rehydration, there are clearly palatability issues that influence the formulation. Effective post-exercise rehydration requires replacement of electrolyte losses as well as the ingestion of a volume of fluid in excess of the volume of sweat loss (Shirreffs et al. 1996). When sweat electrolyte losses are high, replacement with drinks with a high $\mathrm{Na}$ content can result in an unpalatable product. This can be alleviated to a large degree by substituting other anions for the $\mathrm{Cl}^{-}$that is normally added. The addition of carbohydrate has a major impact on taste and mouth feel, and a variety of different sugars with different taste characteristics can be added.

\section{Other active ingredients}

There is a growing trend for the formulation of sports drinks to be modified to include other components which might affect the functional characteristics of the drink. Many of the drinks aimed at the active individual include a range of vitamins and minerals, but it is widely agreed that these are not generally necessary. There is also little convincing evidence for beneficial effects of the addition of purported ergogenic compounds such as taurine, ginseng or aspartate (Williams, 1985). There is rather more experimental evidence to support the use of caffeine (Spriet, 1997), and some evidence that glutamine supplementation may benefit athletes during periods of intensive training (Newsholme \& Castell, 1996), but these compounds are not at present included in any of the commercially-available products.

Glycerol. The difficulties of achieving an adequate fluid intake during many competitive sports events, and the growing recognition of the negative effects of hypohydration have led to an increasing emphasis on ensuring an optimum hydration status before exercise begins. Given the small volumes that it is normally possible to consume during exercise, there would seem to be benefits from ingesting fluid before exercise begins. Athletes are encouraged to consume fluids in the hours before competition to correct any persistent fluid deficit, but the kidneys effectively prevent most of the strategies that have been invoked in attempts to increase water storage before exercise. Water balance is largely controlled by monitoring of the circulating osmolality; this is determined largely by the plasma $\mathrm{Na}$ concentration, as $\mathrm{Na}$ is the major circulating osmotically-active substance, and the osmoreceptor may be in the form of a $\mathrm{Na}$ receptor. Changes in osmolality cause alterations in output of anti-diuretic hormone by the pituitary, and anti-diuretic hormone in turn controls the re-absorption of water by the distal tubule of the nephron and by the collecting duct, thus determining the urine flow.

Some degree of temporary hypervolaemia and hyperhydration result when drinks with high $\mathrm{Na}$ concentrations are ingested, and there may be benefits of this blood volume expansion for the endurance athlete (Luetkemeier et al. 1997). The acute effect of saline ingestion, however, is transient and is rapidly corrected by the appropriate renal response. Attempts have been made to induce a state of relative hyperhydration before exercise by administration of glycerol solutions; ingestion of glycerol results in a marked rise in the extracellular glycerol concentration, and thus osmolality (Gleeson et al. 1986). This has the effect of increasing total body water, but results in an increase in plasma osmolality, and so may be considered to result in a relative hypohydration, even though total body water is increased (Sawka \& Pandolf, 1990). The elevation of the osmolality of the extracellular space may result in water movements from the intracellular space, and cell dehydration, resulting in tissue shrinkage, is a well-recognized consequence of the administration of large amounts of glycerol.

Recently, several studies have reported that ingestion of glycerol together with water can elevate plasma osmolality and increase the total body water content, and that there may be benefits for thermoregulation and exercise performance (Riedesel et al. 1987). Lyons et al. (1990) gave subjects glycerol plus water or water alone $2.5 \mathrm{~h}$ before a 90 min exercise test at $60 \%$ of maximum $\mathrm{O}_{2}$ uptake in a hot $\left(42^{\circ}\right)$ dry $(25 \%$ relative humidity) environment. The addition of glycerol decreased urine output over the trial and resulted in an increased sweat rate and a smaller rise in rectal temperature during the exercise period; there was also a tendency, although not statistically significant, for heart rate to be lower on the glycerol trial. Freund et al. (1995) have also reported an enhanced fluid retention and reduced renal flow when glycerol was added to drinks ingested at rest, and proposed that this effect might be mediated by an effect on anti-diruetic hormone output.

There have also been some recent reports of improvements in the ability to perform prolonged exercise after glycerol administration (Montner et al. 1996). Although not all individuals showed an improvement in performance, they did find that previous administration of glycerol (1.2 $\mathrm{g} / \mathrm{kg}$ ) plus water resulted in significant improvements in time to exhaustion compared with a water-only trial in two exercise tests lasting about $90 \mathrm{~min}$; the improved exercise performance was associated with a lower heart rate during exercise and a smaller rise in core temperature.

The recommendation that endurance athletes competing in the heat should ingest glycerol and water before exercise, or that glycerol should be added to drinks, would seem to 
be premature at this stage, and further developments in this area are awaited with interest.

Branched-chain amino acids (BCAA). Although the subjective sensations of fatigue that accompany prolonged exercise are generally considered to be the result of events occurring in the muscles or the cardiovascular system, there is growing evidence that the signals that arise in the periphery are modulated by events occurring within the central nervous system; this is generally referred to as the central fatigue hypothesis (Davis, 1996). This hypothesis proposes that an increased brain serotonin (5-hydroxytryptamine) concentration is associated with the onset of fatigue; increases in brain 5-hydroxytryptamine can result from an increase in the transport of the precursor tryptophan from the plasma across the blood-brain barrier. Increasing the plasma concentration of BCAA, which are competitive inhibitors of tryptophan uptake, can reduce brain 5-hydroxytryptamine accumulation, and these observations have led to suggestions that BCAA should be added to drinks intended for consumption during prolonged exercise (Davis, 1996).

Although the evidence supporting a role for 5-hydroxytryptamine in the fatigue process seems strong (Wilson \& Maughan, 1992), attempts to improve performance by the administration of BCAA during exercise have not generally been successful. One study (Blomstrand et al. 1991) did show beneficial effects in a subgroup of marathon runners who ingested drinks containing BCAA during the race, but these results have not been reproduced under controlled laboratory conditions (Varnier et al. 1994; Verger et al. 1994; van Hall et al. 1995). In the study of Verger et al. (1994) which involved treadmill-running rats, BCAA feeding resulted in a shorter exercise time to fatigue. Despite these rather unpromising findings, at least one sports drink which contains added BCAA is on sale.

\section{Conclusions}

There is clear evidence that supplying both fluids and an energy source can improve athletic performance. This is as important to the Sunday afternoon football player as to the Olympic athlete. Sports drinks try to meet many different needs, and the formulation of popular products represents a compromise designed to meet the needs of most individuals in most situations. The main needs are to include carbohydrate to support metabolism, and to optimize hydration status by including some sugar and some $\mathrm{Na}$ to stimulate absorption of water. Palatability of the endproduct is a major issue in encouraging consumption. The evidence to support the inclusion of other components is not at present entirely convincing.

\section{References}

Adopo E, Perronet F, Massicote D, Brisson G \& Hilaire-Marcel C (1994) Respective oxidation of exogenous glucose and fructose given in the same drink during exercise. Journal of Applied Physiology 76, 1014-1019.
American College of Sports Medicine (1984) Position stand on prevention of thermal injuries during distance running. Medicine and Science in Sports and Exercise 16, ix-xiv.

Bar-Or O \& Wilk B (1996) Water and electrolyte replenishment in the exercising child. International Journal of Sports Nutrition 6 , 93-99.

Below P, Mora-Rodriguez R, Gonzalez-Alonso J \& Coyle EF (1995) Fluid and carbohydrate ingestion independently improve performance during $1 \mathrm{~h}$ of intense cycling. Medicine and Science in Sports and Exercise 27, 200-210.

Blomstrand E, Hassmen P, Ekblom B \& Newsholme EA (1991) Administration of branched-chain amino acids during endurance exercise - effects on performance and on plasma concentration of some amino acids. European Journal of Applied Physiology 63, 83-88.

Bosch AN, Dennis SC \& Noakes TD (1994) Influence of carbohydrate ingestion on fuel substrate turnover and oxidation during prolonged exercise. Journal of Applied Physiology 76, 2364-2372.

Brener W, Hendrix TR \& McHugh PR (1983) Regulation of the gastric emptying of glucose. Gastroenterology 85, 76-82.

Carter JE \& Gisolfi CV (1989) Fluid replacement during and after exercise in the heat. Medicine and Science in Sports and Exercise 21, 532-539.

Coggan AR \& Coyle EF (1988) Effect of carbohydrate feedings during high-intensity exercise. Journal of Applied Physiology 65, 1703-1709.

Coggan AR \& Coyle EF (1991) Carbohydrate ingestion during prolonged exercise: effects on metabolism and performance. Exercise and Sport Sciences Reviews 19, 1-40.

Costill DL, Bennett A, Branam G \& Eddy D (1973) Glucose ingestion at rest and during prolonged exercise. Journal of Applied Physiology 34, 764-769.

Costill DL \& Sparks KE (1973) Rapid fluid replacement following thermal dehydration. Journal of Applied Physiology 34, 299303.

Coyle EF (1997) Fuels for sport performance. In Perspectives in Exercise Science and Sports Medicine, vol. 10, Optimising Sport Performance, pp. 95-138 [DR Lamb and R Murray, editors]. Carmel: Benchmark Press.

Coyle EF, Coggan AR, Hemmert MK \& Ivy JL (1986) Muscle utilization during prolonged strenuous exercise when fed carbohydrate. Journal of Applied Physiology 61, 165-172.

Coyle EF, Hagberg JM, Hurley BF, Martin WH, Ehsani AH \& Holloszy JO (1983) Carbohydrate feeding during prolonged strenuous exercise can delay fatigue. Journal of Applied Physiology 55, 230-235.

Coyle EF \& Hamilton M (1990) Fluid replacement during exercise: effects on physiological homeostasis and performance. In Perspectives in Exercise Science and Sports Medicine, vol. 3, Fluid Homeostasis During Exercise, pp. 281-308 [CV Gisolfi and DR Lamb, editors]. Carmel: Benchmark Press.

Davis JM (1996) Nutritional influences on central mechanisms of fatigue involving serotonin. In Biochemistry of Exercise, vol. 9, pp. 445-455 [RJ Maughan and SM Shirreffs, editors]. Champaign, IL: Human Kinetics.

Davis JM, Burgess WA, Slentz CA, Bartoli WP \& Pate RR (1988) Effects of ingesting $6 \%$ and $12 \%$ glucose/electrolyte beverages during prolonged intermittent cycling in the heat. European Journal of Applied Physiology 57, 563-569.

Erickson MA, Schwartzkopf RJ \& McKenzie RD (1987) Effects of caffeine, fructose, and glucose ingestion on muscle glycogen utilisation during exercise. Medicine and Science in Sports and Exercise 19, 579-583.

Farthing MJG (1994) Oral rehydration therapy. Pharmacological Therapeutics 64, 477-492. 
Fordtran JS (1975) Stimulation of active and passive sodium absorption by sugars in the human jejunum. Journal of Clinical Investigation 55, 728-737.

Freund BJ, Montain SJ, Young AJ, Sawka MN, DeLuca JP, Pandolf KB \& Valeri CR (1995) Glycerol hyperhydration: hormonal, renal and vascular fluid responses. Journal of Applied Physiology 79, 2069-2077.

Frizell RT, Lang GH, Lowance DC \& Lathan SR (1986) Hyponatraemia and ultramarathon running. Journal of the American Medical Association 255, 772-774.

Gisolfi CV, Summers RW \& Schedl HP (1990) Intestinal absorption of fluids during rest and exercise. In Perspectives in Exercise Science and Sports Medicine, vol. 3, Fluid Homeostasis during Exercise, pp. 129-186 [CV Gisolfi and DR Lamb, editors]. Carmel: Benchmark Press.

Gleeson M, Maughan RJ \& Greenhaff PL (1986) Comparison of the effects of pre-exercise feeding of glucose, glycerol and placebo on endurance and fuel homeostasis in man. European Journal of Applied Physiology 55, 645-653.

Gonzalez-Alonso J, Heaps CL \& Coyle EF (1992) Rehydration after exercise with common beverages and water. International Journal of Sports Medicine 13, 399-406.

Gregory J, Foster K, Tyler H \& Wiseman M (1990) The Dietary and Nutritional Survey of British Adults. London: H. M. Stationery Office.

Hargreaves M \& Briggs CA (1988) Effect of carbohydrate ingestion on exercise metabolism. Journal of Applied Physiology 65, 1553-1555.

Hargreaves M, Costill DL, Coggan A, Fink WJ \& Nishibata I (1984) Effect of carbohydrate feedings on muscle glycogen utilisation and exercise performance. Medicine and Science in Sports and Exercise 16, 219-222.

Hiller WDB (1989). Dehydration and hyponatraemia during triathlons. Medicine and Science in Sports and Exercise 21, S219-S221.

Hubbard RW, Sandick BL, Matthew WT, Francesconi RP, Sampson JB, Durkot MJ, Maller O \& Engel DB (1984) Voluntary dehydration and alliesthesia for water. Journal of Applied Physiology 57, 868-875.

Hubbard RW, Szlyk PC \& Armstrong LE (1990) Influence of thirst and fluid palatability on fluid ingestion during exercise. In Perspectives in Exercise Science and Sports Medicine, vol. 3, Fluid Homeostasis during Exercise, pp. 39-95 [CV Gisolfi and DR Lamb, editors]. Carmel: Benchmark Press.

Ivy J, Costill DL, Fink WJ \& Lower RW (1979) Influence of caffeine and carbohydrate feedings on endurance performance. Medicine and Science in Sports and Exercise 11, 6-11.

Jones BJM, Brown BE, Loran JS, Edgerton D \& Kennedy JF (1983) Glucose absorption from starch hydrolysates in the human jejunum. Gut 24, 1152-1160.

Jones BJM, Higgins BE \& Silk DBA (1987) Glucose absorption from maltotriose and glucose oligomers in the human jejunum. Clinical Science 72, 409-414.

Lamb DR \& Brodowicz GR (1986) Optimal use of fluids of varying formulations to minimize exercise-induced disturbances in homeostasis. Sports Medicine 3, 247-274.

Luetkemeier MJ, Coles MG \& Askew EW (1997) Dietary sodium and plasma volume levels with exercise. Sports Medicine 23, 279-286.

Lyons T, Riedesel ML, Meuli LE \& Chick TW (1990) Effects of glycerol-induced hyperhydration prior to exercise in the heat on sweating and core temperature. Medicine and Science in Sports and Exercise 22, 477-483.

McConnell G, Fabris S, Proietto J \& Hargreaves M (1994) Effect of carbohydrate ingestion on glucose kinetics during exercise. Journal of Applied Physiology 77, 1537-1541.
Massicote D, Péronnet F, Brisson G, Bakkouch K \& HilaireMarcel C (1989) Oxidation of a glucose polymer during exercise: comparison with glucose and fructose. Journal of Applied Physiology 66, 179-183.

Maughan RJ (1986) Exercise-induced muscle cramp: a prospective biochemical study in marathon runners. Journal of Sports Science 4, 31-34.

Maughan RJ (1994) Fluid and electrolyte loss and replacement in exercise. In Oxford Textbook of Sports Medicine, pp. 82-93 [M Harries, C Williams, WD Stanish and LL Micheli, editors]. Oxford: Oxford University Press.

Maughan RJ, Bethell L \& Leiper JB (1996) Effects of ingested fluids on homeostasis and exercise performance in man. Experimental Physiology 81, 847-859.

Maughan RJ, Fenn CE, Gleeson M \& Leiper JB (1987) Metabolic and circulatory responses to the ingestion of glucose polymer and glucose/electrolyte solutions during exercise in man. European Journal of Applied Physiology 56, 356-362.

Maughan RJ \& Leiper JB (1995) Effects of sodium content of ingested fluids on post-exercise rehydration in man. European Journal of Applied Physiology 71, 311-319.

Maughan RJ, Owen JH, Shirreffs SM \& Leiper JB (1994) Postexercise rehydration in man: effects of electrolyte addition to ingested fluids. European Journal of Applied Physiology 69, 209-215.

Mitchell JB, Costill DL, Houmard JA, Flynn MG, Fink WJ \& Beltz JD (1988) Effects of carbohydrate ingestion on gastric emptying and exercise performance. Medicine and Science in Sports and Exercise 20, 110-115.

Montner P, Stark DM, Riedesel ML, Murata G, Robergs R, Timms M \& Chick TW (1996) Pre-exercise glycerol hydration improves cycling endurance time. International Journal of Sports Medicine 17, 27-33.

Murray R (1987) The effects of consuming carbohydrateelectrolyte beverages on gastric emptying and fluid absorption during and following exercise. Sports Medicine 4, 322-351.

Murray R, Eddy DE, Murray TW, Seifert JG, Paul GL \& Halaby GA (1987) The effect of fluid and carbohydrate feedings during intermittent cycling exercise. Medicine and Science in Sports and Exercise 19, 597-604.

Nadel ER, Mack GW \& Nose H (1990) Influence of fluid replacement beverages on body fluid homeostasis during exercise and recovery. In Perspectives in Exercise Science and Sports Medicine, vol. 3, Fluid Homeostasis during Exercise, pp 181-205 [CV Gisolfi and DR Lamb, editors]. Carmel: Benchmark Press.

Newsholme EA \& Castell LM (1996) Can amino acids influence exercise performance in athletes? In The Physiology and Pathophysiology of Exercise Tolerance, pp. 269-274 [JM Steinacker and SA Ward, editors]. New York: Plenum Press.

Nielsen B, Sjogaard G, Ugelvig J, Knudsen B \& Dohlmann B (1986) Fluid balance in exercise dehydration and rehydration with different glucose-electrolyte drinks. European Journal of Applied Physiology 55, 318-325.

Noakes TD (1990) The dehydration myth and carbohydrate replacement during prolonged exercise. Cycling Science 1, 2329.

Noakes TD (1993) Fluid replacement during exercise. In Exercise and Sports Science Reviews, vol. 21, pp. 297-330 [JO Holloszy, editor]. Baltimore, MD: Williams \& Wilkins.

Noakes TD, Goodwin N, Rayner BL, Branken T \& Taylor RKN (1985) Water intoxication: a possible complication during endurance exercise. Medicine and Science in Sports and Exercise 17, 370-375.

Noakes TD, Norman RJ, Buck RH, Godlonton J, Stevenson K \& Pittaway D (1990) The incidence of hyponatremia during 
prolonged ultraendurance exercise. Medicine and Science in Sports and Exercise 22, 165-170.

Nose H, Mack GW, Shi X \& Nadel ER (1988a) Role of osmolality and plasma volume during rehydration in humans. Journal of Applied Physiology 65, 325-331.

Nose H, Mack GW, Shi X \& Nadel ER (1988b) Involvement of sodium retention hormones during rehydration in humans. Journal of Applied Physiology 65, 332-336.

Pirnay F, Crielaard JM, Pallikarakis N, Lacroix M, Mosora F, Krzentowski G, Luyckx AS \& Lefebvre PJ (1982) Fate of exogenous glucose during exercise of different intensities in humans. Journal of Applied Physiology 53, 1620-1624.

Pirnay F, Lacroix M, Mosora F, Luyckx A \& Lefebvre P (1977) Glucose oxidation during prolonged exercise evaluated with naturally labeled $\left[{ }^{13} \mathrm{C}\right]$ glucose. Journal of Applied Physiology 43, 258-261.

Rehrer NJ (1990) Limits to Fluid Availability During Exercise. Haarlem, The Netherlands: De Vriesebosch.

Riedesel ML, Allen DL, Peake GT \& Al-Qattan K (1987) Hyperhydration with glycerol solutions. Journal of Applied Physiology 63, 2262-2268.

Sasaki H, Maeda J, Usui S \& Ishiko T (1987) Effect of sucrose and caffeine ingestion on performance of prolonged stren uous running. International Journal of Sports Medicine 8 , 261-265.

Sawka MN \& Pandolf KB (1990) Effects of body water loss on physiological function and exercise performance. In Perspectives in Exercise Science and Sports Medicine, vol. 3. Fluid Homeostasis during Exercise, pp. 1-38 [CV Gisolfi and DR Lamb, editors]. Carmel: Benchmark Press.

Shi X, Summers RW \& Schedl HP (1995) Effect of carbohydrate type and concentration and solution osmolality on water absorption. Journal of Applied Physiology 27, 1607-1615.

Shirreffs SM \& Maughan RJ (1997) Whole body sweat collection in man: an improved method with some preliminary data on electrolyte composition. Journal of Applied Physiology 82, 336-341.

Shirreffs SM, Taylor AJ, Leiper JB \& Maughan RJ (1996) Postexercise rehydration in man: effects of volume consumed and sodium content of ingested fluids. Medicine and Science in Sports and Exercise 28, 1260-1271.

Spiller RC, Jones BJM, Brown BE \& Silk DBA (1982) Enhancement of carbohydrate absorption by the addition of sucrose to enteric diets. Journal of Parenteral and Enteral Nutrition 6, 321.
Spriet LL (1997) Ergogenic aids: recent advances and retreats. In Perspectives in Exercise Science and Sports Medicine, vol. 10, Optimising Sport Performance, pp. 185-238 [DR Lamb and R Murray, editors]. Carmel: Benchmark Press.

Szlyk PC, Sils IV, Francesconi RP, Hubbard RW \& Armstrong LE (1989) Effects of water temperature and flavoring on voluntary dehydration in men. Physiology and Behavior 45, 639-647.

Tsintzsas OK, Liu R, Williams C, Campbell I \& Gaitanos G (1993) The effect of carbohydrate ingestion on performance during a 30-km race. International Journal of Sport Nutrition 3, 127-139.

van Hall G, Raaymakers JSH, Saris WHM \& Wagenmakers AJM (1995) Ingestion of branched-chain amino acids and tryptophan during sustained exercise - failure to affect performance. Journal of Physiology 486, 789-794.

Varnier M, Sarto P, Martines D, Lora L, Carmignoto F, Leese G \& Naccarato $R$ (1994) Effect of infusing branched-chain amino acids during incremental exercise with reduced muscle glycogen content. European Journal of Applied Physiology 69, 2631 .

Verger PH, Aymard P, Cynobert L, Anton G \& Luigi R (1994) Effects of administration of branched-chain amino acids vs. glucose during acute exercise in the rat. Physiology and Behavior 55, 523-526.

Vist GE \& Maughan RJ (1994) The effect of increasing glucose concentration on the rate of gastric emptying in man. Medicine and Science in Sports and Exercise 26, 1269-1273.

Vist GE \& Maughan RJ (1995) The effect of osmolality and carbohydrate content on the rate of gastric emptying of liquids in man. Journal of Physiology 486, 523-531.

Wagenmakers AJM, Brouns F, Saris WH \& Halliday D (1993) Oxidation rates of orally ingested carbohydrates during prolonged exercise in men. Journal of Applied Physiology 75 2774-2780.

Wapnir RA \& Lifshitz F (1985) Osmolality and solute concentration - their relationship with oral rehydration solution effectiveness: an experimental assessment. Pediatric Research 19, 894-898.

Williams MH (1985) Nutritional Aspects of Human Physical and Athletic Performance. Springfield, $\Pi$ : CC Thomas.

Wilson WM \& Maughan RJ (1992) A role for serotonin in the genesis of fatigue in man: administration of a 5-hydroxytryptamine reuptake inhibitor (Paroxetine) reduces the capacity to perform prolonged exercise. Experimental Physiology 77, 921924. 